\title{
David Delfín y el arte del siglo XX y XXI
}

Ismael Amaro Martos*

Universidad de Jaén

RECIBIDO: 20.01.2018 / ACEPTADO: 05.03.2018

\section{Resumen}

David Delfín aseguró que su trabajo se movía por ideas y emociones. A través de este artículo pretendemos desarrollar la influencia que otros artistas plásticos del siglo XX y XXI ejercieron en su obra. La polémica que en ocasiones acarrearon los diseños del artista malagueño no hubiera sido tal si los medios de comunicación no hubiesen llevado a cabo una lectura vacía de sus desfiles y demás proyectos artísticos. Por fortuna el paso del tiempo les hizo comprender que David Delfín no era un diseñador al uso y que la valoración de sus propuestas no podía limitarse a un juicio estético. Para emitir una opinión acertada de su universo creativo había que acercarse a sus sentimientos y, muy especialmente, como atenderemos en esta ocasión, a los estilos y artistas que contribuyeron a la conformación de su identidad.

Palabras clave: David Delfín, diseño, moda, arte, identidad.

\section{David Delfín and the art of 20th and 21st centuries}

\section{Abstract}

David Delfin claimed that his job moved around ideas and feelings. Throughout this article we pretend to develop the influence of other plastic artists of the 20th and 21st centuries on his work. The polemic, which sometimes had the designs of the Malaga artist, would not have been like that if the media had not made an empty interpretation of his fashion shows. Fortunately, the trace of time made it understand that David Delfin is not a typical designer and the valuation of his designs could not be limited just to an aesthetic judgement. In order to give a more definite view of his creative universe we must approach to his feelings, and specially like we adress to in this ocassion, to the styles and artists which contribute to the forming of his identity.

Keywords: David Delfin, design, fashion, art, identity. 


\section{Introducción}

La historia del diseño de moda contemporáneo en España está llena de grandes genios, empezando por Mariano Fortuny y Madrazo y llegando hasta Ágatha Ruiz de la Prada, pasando por el genio Cristóbal Balenciaga y sus contemporáneos Manuel Pertegaz, Elio Berhanyer o Antonio Castillo. Uno de los talentos de fama internacional del siglo XXI ha sido Diego David Domín guez González, David Delfín ${ }^{1}$. Aunque él siempre defendió que no eligió trabajar en moda, sino que la moda le eligió a él ${ }^{2}$, llegó a convertirse en una leyenda del sector prácticamente desde que pusiera el pie en la pasarela de Madrid en el año $2002^{3}$. Sus inicios como artista visual comenzaron a través de la pintura, en 1999, cuando, después de haber trabajado sobre papel, lienzo, madera y cartón, buscó nuevos soportes ${ }^{4}$. Su búsqueda acabó con la reutilización de prendas militares de segunda mano. Estas comportaban una memoria, huellas de aquellos que las llevaron (nombres, manchas, zurcidos, etc.), en las que incluía la que se convirtió en su seña de identidad: su tipografía ${ }^{5}$. Sus textos, escritos con la mano izquierda, dieron lugar a una caligrafía torpe, como la de un niño primerizo, en una evolución similar a la de su paisano Picasso, que empezó pintando realista y acabó haciéndolo como un niño6.

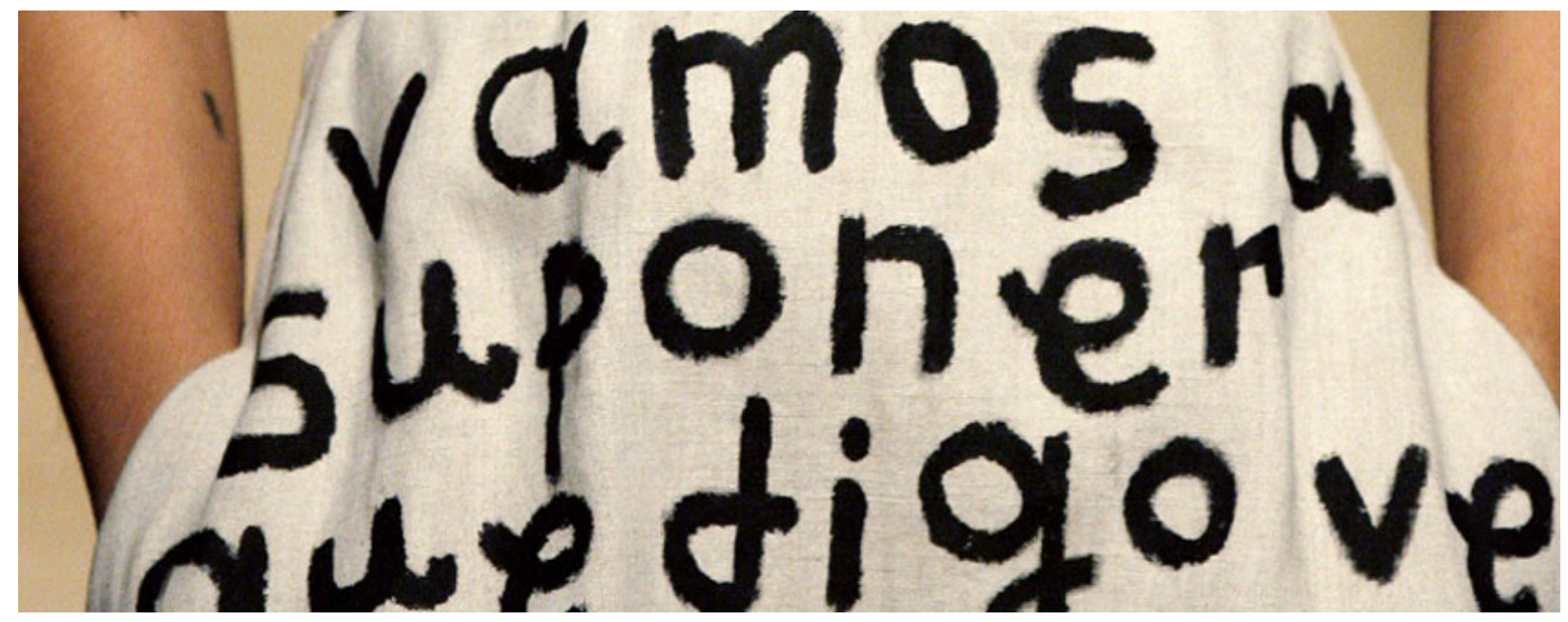

Fig. 1. DAFO, primavera/verano 2007.

1 AMARO MARTOS, I. "Diseño de moda español. Manifiesto a favor del reconocimiento internacional de su identidad" en i+Diseño: revista internacional de investigación, innovación y desarrollo en diseño núm. 12, Málaga, abril 2013, p. 7.

2 DELFÍN, D. El saber no sabido ¿Elegí la moda o la moda me eligió a mi? [Curso Magistral Ideas y Emociones], Universidad Internacional Menéndez Pelayo, Santander (01.07.2013).

3 Colección Cour des Miracles, primavera/verano 2003.

4 DELFÍN, D. Cómo llego al mundo de la moda [Curso Magistral Ideas y Emociones], Universidad Internacional Menéndez Pelayo, Santander (01.07.2013).

5 GARCÍA GARRIDO, S. "David Delfín (Ronda 1970-Madrid 2017). Memorian in Academiae Arts" en Anuario. Real Academia de Bellas Artes de San Telmo de Málaga, Málaga 2017.

6 DELFÍN, D. Inspiraciones [Curso Magistral Ideas y Emociones], Universidad Internacional Menéndez Pelayo, Santander (03.07.2013). 
Sus obras, pintura e indumentaria a la vez, tenían la capacidad de vestir, ya que indirectamente comportaban su uso originario. La particularidad de sus piezas motivó que editores de moda y pasarelas se interesasen por su trabajo. Y así es como llegó a crear una colección titulada Openin Nite para la pasarela de moda alternativa de Barcelona, el Circuit, en 20017. Un año después ya estaba en Madrid presentando Cour des Miracles ${ }^{8}$. Ambas muestras tuvieron discursos vertebradores marcados por la influencia de artistas del siglo $\mathrm{XX}$, algo que continuó en las siguientes colecciones y aportaciones a tantos otros ámbitos del diseño, con estos y otros creadores, alcanzando incluso artífices de su tiempo. David Delfín, consciente de que "sólo si renunciamos a ser completos podremos desear algo de otros", aceptó que otros artistas entrasen en su obra ${ }^{10}$, influenciando, sustentando y construyendo "una mujer de cuatro cabezas" llamada "davidelfin"11.

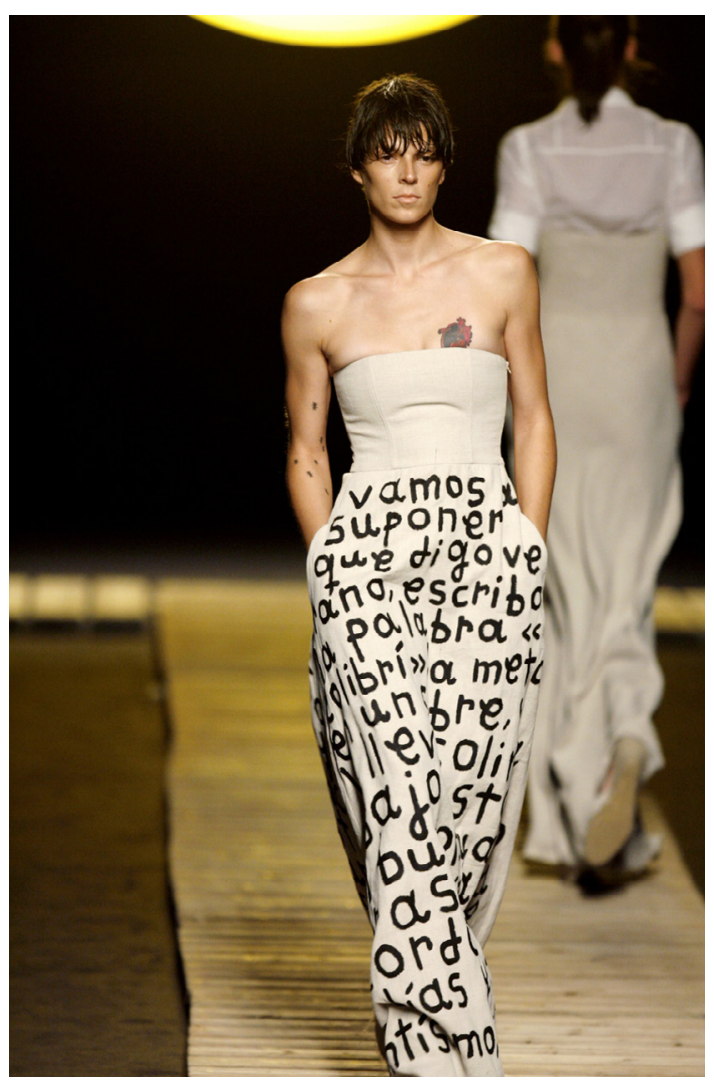

Fig. 2. DAFO, primavera/verano 2007.

\footnotetext{
7 Primavera/verano 2002. DELFíN, D. Los comienzos [Curso Magistral Ideas y Emociones], Universidad Internacional Menéndez Pelayo, Santander (01.07.2013).

8 Primavera/verano 2003.

9 DELFíN, D. Inspiraciones [Curso Magistral Ideas y Emociones], Universidad Internacional Menéndez Pelayo, Santander (03.07.2013).

10 AMARO MARTOS, I. Diseño de moda en España. Estudio para una identidad internacional [Trabajo Fin de Máster (inédito), Tutor: Sebastián García Garrido]. Universidad de Málaga, Málaga 2013, p. 52.

11 La firma Davidelfin fue creada en 2001 por los hermanos Postigo (Deborah, Gorka y Diego), David Delfín y Bimba Bosé. Se trató de un proyecto multidisciplinar que aunaba moda, fotografía, arquitectura y video. DELFÍN, D. davidelfin/plural ¿Una mujer de cuatro cabezas? [Curso Magistral Ideas y Emociones], Universidad Internacional Menéndez Pelayo, Santander (02.07.2013).
} 


\section{Referencias a artistas plásticos contemporáneos en el legado de David Delfín}

\subsection{Joseph Beuys}

Cuando aún no se había subido a la pasarela, y pintaba sobre los uniformes militares ajados, su trabajo ya giraba en torno al pensamiento, vida y obra de Joseph Beuys ${ }^{12}$. Este artista alemán le acompañó hasta una de sus últimas intervenciones, la serie de retratos realizada por el fotógrafo de moda Pablo Sáez, en la que "enseñaba su herida"13. Y es que la propia selección del soporte elegido para los trajes de su primera colección pasaba por un influjo de Beuys, piloto excombatiente de la Luftwaffe en la Segunda Guerra Mundial ${ }^{14}$. Referencias militares que también se repitieron en su colección PATER, en la que los modelos portaban elementos característicos de los soldados alemanes, como las terminaciones de los cuellos de las camisas o los brazaletes rojos sobre chaquetas de corte militar estilo años cuarenta ${ }^{15}$.

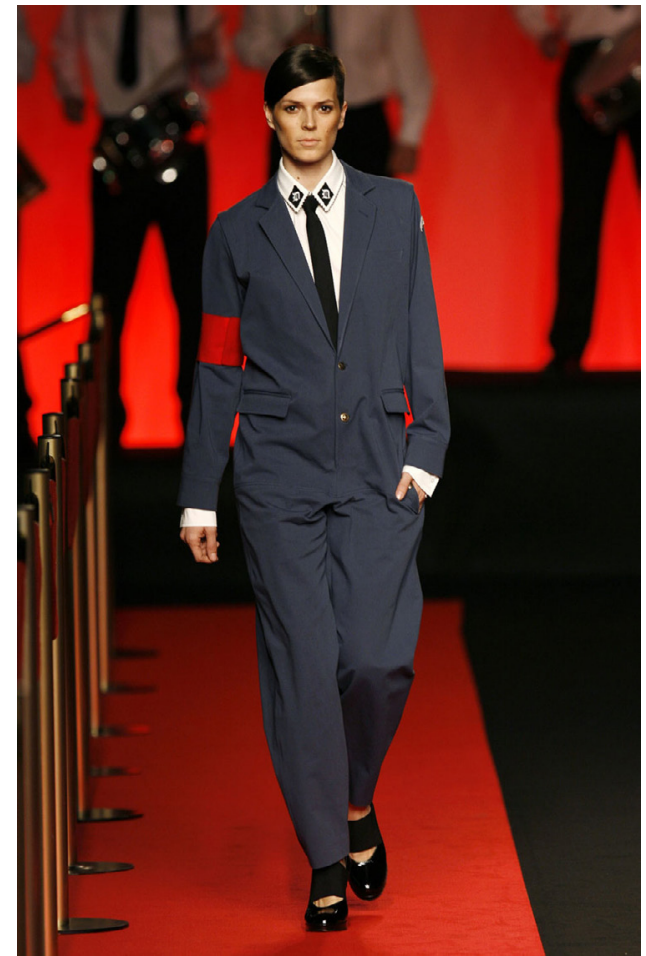

Fig. 3. PATER, otoño/invierno 2006.

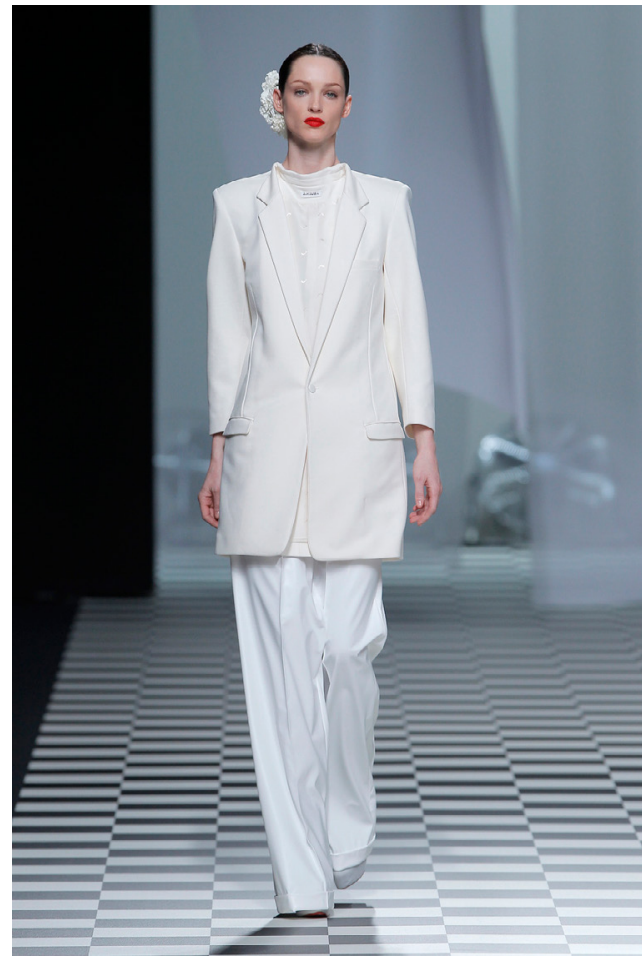

Fig. 4. Missing, otoño/invierno 2013.

\section{GARCÍA GARRIDO, S. Op. cit.}

13 David Delfín llevaba tatuado Muestra tu herida en alemán (zeige deine Wunde), el nombre de una instalación de Beuys en Munich, realizada en febrero de 1976. Los elementos utilizados se conservan en el museo Lenbachhaus de la misma ciudad. The Collection Joseph Beuys. <http://www.lenbachhaus.de/collection/joseph-beuys/?L=1> (01.08.2017). Fotografías de los elementos utilizados: Núm. de inv. AR00093. BEUYS, J. Show Your Wound, 1977 (6 negativos de fotografía 238x330 mm. Tate Gallery, London/National Galleries of Scotland, Edimburgo). Las fotografías fueron portada de la edición impresa de Vogue España, julio 2016. En la edición digital desde el 21 de junio del mismo año. La lucha de David Delfín, 2016 <http://www.vogue.es/moda/news/articulos/david-delfin-habla-por-primera-vez-operacion-tumores-vogue-espana/25999> (01.08.2017).

14 MESCH, C./MICHELY, V. Joseph Beuys. The reader. Tauris, London 2007, p. 59.

15 Otoño/invierno 2006. 
En la colección Demenagement volvió a hacer claras alusiones a Joseph Beuys ${ }^{16}$. En primer lugar con la elección de los propios materiales, existiendo un predominio del fieltro, utilizado en numerosas ocasiones por el exmilitar, como en Traje de fieltro ${ }^{17}$. Además, la disposición de este tejido sobre el cuerpo, especialmente en los looks dos y tres de su colección ${ }^{18}$, son una clara alusión a la famosa acción del artista alemán Me gusta América y a América le gusto yo, llevada a cabo en mayo de 1974 en la René Block Gallery de Nueva York ${ }^{19}$.

A esto debemos añadir la supervivencia de motivos puramente "Beuys" en otros ámbitos del diseño y en la ropa, como la cruz roja con y sin sello, que se incluyó en muchas de las camisetas básicas de la firma, continuando las referencias a la biografía del artista alemán ${ }^{20}$. En la colección Intimidad recreó la soledad de un campo de concentración, con altas vallas terminadas en espinas ${ }^{21}$. Al retomar la vida de Joseph Beuys, su pasado militar y su relación con el ejército alemán, es inevitable descontextualizar y desligar las referencias bélicas encontradas en las obras de David Delfín del que fue su artista más admirado y el que más le influenció.

\subsection{René Magritte, Luis Buñuel y el surrealismo}

La primera colección con la que David Delfín comenzó a ser reconocido fue la citada Cour des Miracles, su debut en Madrid. Dalí dijo en su día: "Que hablen bien o mal, lo importante es que hablen de mí". Eso es lo que debería haber pensado David cuando todos los medios de comunicación se le echaron encima por su colección, pero no fue así. Muestra que, justamente, estaba inspirada en el surrealismo y pocos supieron reconocer. El desfile fue abierto con un vestido blanco decorado con hormigas, un guiño descarado a Luis Buñuel y Salvador Dalí en Un perro andaluz, recordando la famosa escena de la mano ${ }^{22}$. Las modelos encapuchadas no simulaban burkas como se dijo, sino que ocultaban su identidad como Los amantes de Magritte ${ }^{23}$. De hecho, la colección

16 Otoño/invierno 2007.

17 Núm. de inv. T07441. BEUYS, J. Felt Suit, 1970 (fieltro 170x60 cm. Tate Gallery, London).

18 DELFíN, D. Demenagement, fall/winter 2007, 2006 <http://www.davidelfin.com/es/coleccion/demenagement> (01.08.2017)

19 Joseph Beuys fue envuelto en fieltro y llevado en ambulancia hasta galería, para así no pisar suelo americano, ya que se oponía a las acciones militares que el gobierno estadounidense emprendió en Vietnam. Evidentemente el título del happening estaba cargado de ironía. En la galería estuvo encerrado tres días con un coyote, sólo con guantes, un bastón y el fieltro que lo envolvía, elementos que conjugaron escenas escultóricas en su desarrollo. Cada día se introducían cincuenta copias del Wall Street Journal. El coyote respondió orinando sobre estos. Por su parte, Beuys realizaba las mismas acciones mirando fijamente al animal. Otras veces descansaba o recogía el fieltro a su alrededor, sugiriendo la figura de un pastor. El comportamiento del coyote varió con el transcurrir de los días, volviéndose cauteloso, indiferente, agresivo, e incluso llegó a dar compañía. Room 4 <http://www.tate.org.uk/whats-on/tate-modern/ exhibition/joseph-beuys-actions-vitrines-environments/joseph-beuys-actions-4> (01.08.2017) Documentado en: núm. de inv. AR00728. BEUYS, J. Joseph Beuys: I Like America and America Likes Me (Documentation of a Performance at the René Block Gallery, New York, may '74), Richard Demarco Gallery, Edinburgh, 1974 (pintura sobre papel 80,4x53,4 cm. Tate, London/National Galleries of Scotland, Edimburgo)

20 Algunos de los diseños en los que ha incluido referencias a Beuys son: funda para consola Play Station PSP de Sony (cruz roja, sello y fondo de camuflaje), dirección de arte del videoclip "Ojalá, ojalá" de Miguel Bosé (cruz roja y coreografía e uniformes militares), desfile-acción Cosas del surrealismo en el Museo Guggenheim de Bilbao (alambrada con espinas), diseño del coche Coupé-Cabriolet para Ford (cruz roja y sello), colección de alfombras para la empresa DAC (cruz roja y sello), etiqueta para el aceite de oliva virgen extra de cultivo ecológico Capricho Andaluz (cruz roja) y vestuario para la Compañía Nacional de Danza-Nippon Koku (uniformes militares estilo años cuarenta). El sello es una constante en los dibujos cartas de Joseph Beuys. La cruz roja aparece, por ejemplo, en: núm. de inv. AM 1976-7. BEUYS, J. Infiltration homogen für Konzertflügel, 1966 (piano, fieltro, tela 100×152×240 cm. Centre Pompidou, Paris).

21 Otoño/invierno 2008.

22 BUÑUEL, L. Un chien andalou, 1929 (película $35 \mathrm{~mm}$ transferida a vídeo. Obra cedida temporalmente para la presentación de la Colección del Museo Nacional Centro de Arte Reina Sofía. Cortesía de Filmoteca Española, Madrid).

23 Núm. de inv. 530.1998. MAGRITTE, R. The Lovers, 1928 (óleo sobre lienzo 54x73,4 cm. MOMA, Nueva York). 
toma su nombre del barrio parisino ocupado por mendigos y lisiados que durante el día pedían limosna y por la noche "se curaban" milagrosamente; estos escondían, pues, su verdadera realidad²4.

Las influencias surrealistas continuaron con Cuerpo extraño ${ }^{25}$. La sastrería jugó un papel importantísimo en la configuración de esta colección. Del mismo modo que los artistas pertenecientes a esta corriente deformaron los cuerpos hasta darles siluetas impropias de su ser, David Delfín dislocó, como si de un cubo de Rubik se tratase, las siluetas de las modelos. La configuración ilógica de estas estructuras llegó a resultados tan interesantes como espaldas en el pecho, cuellos en la cintura o mangas en las caderas. Nuevos posicionamientos de la ropa sobre el cuerpo que aparecieron mucho antes de que lo hiciera John Galliano para Maison Margiela, o Demna Gvasalia para Balenciaga, y que David reutilizó posteriormente en Missing ${ }^{26}$.

Tras exponer en la desaparecida Galería Soledad Lorenzo, en 200427, llevó el concepto del Cuerpo extraño al Centro de Arte Contemporáneo de Málaga ${ }^{28}$. En este video performance, realizado por Diego Postigo, con música de Gabriel Gutiérrez y protagonizado por la bailarina Caliope, la danza casi contorsionista cobra un papel principal. De una mujer brota otra, la misma, y ambas bailan el mismo estilo pero de diferente modo. La confrontación establecida entre la mujer movida por la conciencia y la que lo hace por impulsos del subconsciente revela la importancia del psicoanálisis en los trabajos de David Delfín ${ }^{29}$. De hecho, el malagueño aseguró solucionar los problemas de la empresa davidelfin a través de esta técnica ${ }^{30}$.

Con motivo de la exposición Cosas del Surrealismo del Museo Guggenheim Bilbao, entre el 29 de febrero de 2008 y el 7 de septiembre de ese mismo año ${ }^{31}$, David Delfín ideó un desfile de moda surrealista compuesto por piezas exclusivas y algunas presentadas en anteriores colecciones, como el vestido horca ${ }^{32}$. A través de esta muestra se pretendía descubrir la influencia de este movimiento en el teatro, la decoración de interiores, la moda, el cine, la arquitectura y la publicidad. Ello le valió el título de "heredero" del surrealismo ${ }^{33}$.

24 Aparece en la novela Notre-Dame de Paris. 1482 (1831), de Víctor Hugo. A esta historia debemos la famosa película: DISNEY, Walt. El jorobado de Notre Dame, 1996.

25 Otoño/invierno 2004.

26 Otoño/invierno 2013. Aunque en esta ocasión se limitó a crear un efecto óptico de colocación de la prensa sobre el modelo sin que aparentemente el cuerpo estuviera dentro del traje. Las etiquetas quedaban a la vista y, tras esta falsa disposición, se encontraba la verdadera pieza que cubría.

27 MANSILLA VIEMA, P. Cazadores de tendencias. Los nombres esenciales de la moda española. Lunwerg, Barcelona 2013 , p. 48.

28 CASTRO FLÓREZ, F. Davidelfin. Cuerpo extraño/odd body. 11 junio/29 agosto, 2004. Centro de Arte Contemporáneo de Málaga (cat. expo.), Ayuntamiento de Málaga, Málaga 2004.

29 El diseñador fue un gran seguidor de los dictámenes de Freud. De acuerdo al psicoanálisis freudiano, el arte es una vía de escape de los impulsos reprimidos. El hombre está consumido de deseos y los satisface a través del arte. BAUDOIN, C. Psicoanálisis del arte. Psique, Buenos Aires 1972, pp. 56 y 60. Éstos vienen del inconsciente y salen a la luz enmascarados para pasar la censura de la conciencia. GROMBRICH, E. H. Freud y la psicología del arte. Estilo, forma y estructura a la luz del psicoanálisis. Barral, Barcelona 1971, p. 90. Para poder entender estos símbolos habría que analizar la biografía del artista y así poder llevar a cabo su interpretación. FREUD, S. Psicoanálisis del arte. Alianza, Madrid 1985. Estas premisas no sólo acompañaron a David en el citado video performance, sino que constituyeron una constante en toda su trayectoria, dejando salir sus emociones a través de sus obras/colecciones.

30 DELFÍN, D. davidelfin/plural ¿Una mujer de cuatro cabezas? [Curso Magistral Ideas y Emociones], Universidad Internacional Menéndez Pelayo, Santander (02.07.2013).

31 Nota de prensa del 29 agosto de 2008, emitida por el Museo Guggenheim Bilbao.

32 Este fue el penúltimo look del desfile, llevado por Bimba Bosé, con falda de raso beis pardo y soga al cuello. Para la muestra se optó por un mismo vestido en color negro.

33 GPS, El Guggenheim acogerá un Desfile-Acción de David Delfín con motivo de la muestra Cosas del Surrealismo, 2008. <http:// www.elcorreo.com/vizcaya/ocio/gps/arte/300508/guggenheim-david-delfin.html> (18.10.2017) 


\subsection{Michelangelo Pistoletto y el arte povera}

En la ya citada colección Demenagement (del francés "mudanza") mostró una serie de looks copados por el fieltro de color gris y marrón, antaño utilizados para envolver muebles cuando se cambiaba de hogar. Un desfile sumido en el recuerdo, donde rescata todas las piezas del desván. Objetos recuperados que vuelven a ver la luz y ser reutilizados para no caer en el olvido. En este comportamiento existe una evidente conexión con el arte povera o arte pobre. Y es que, aunque de forma incuestionable asociemos esta tendencia artística al uso de materias primas y pobres, así como elementos desechados por la sociedad, el verdadero fin de esta corriente parte de una encrucijada de recuerdos y evocaciones frente al progreso y la modernidad. Esta concepción se entiende desde la ambigüedad italiana en la que nace, dotada de un glorioso pasado y un inestable siglo $\mathrm{XX}^{34}$

Uno de los grandes representantes del arte povera es Michelangelo Pistoletto. A partir de los años sesenta del siglo pasado, momento clave de la historia del arte italiana e internacional, la obra de Pistoletto desarrolló la parte estética, conceptual y emotiva de este estilo artístico a través de grandes montañas de ropa desechada junto a esculturas o cristales de gran formato ${ }^{35}$. La influencia del artista italiano es innegable en la puesta en escena llevada a cabo en el desfile de Síndrome de Diógenes ${ }^{36}$. Al principio de la pasarela colocó un cerro de ropa usada a la manera de Pistoletto, como ocurriera, por ejemplo, en su obra Venere degli stracci ${ }^{37}$. En el caso de Delfín, se trataba de una acumulación de emociones, incapaces de mantener un orden y culpables de la angustia del diseñador por intentar deshacerse de ellas; convertir el desasosiego en arte se volvió en algo habitual en las colecciones del malagueño ${ }^{38}$.

\subsection{Louise Bourgeois}

Louise Bourgeois fue una artista atormentada, como ella misma explicó: "me dedico al dolor para dar sentido y forma a la frustración y el sufrimiento. No puedo hacer desaparecer el dolor. Ha venido para quedarse". Jerry Gorovoy, su asistente personal, hizo por aclarar sus palabras: "tenía sus problemas psicológicos, claro, mucha ansiedad, temores, miedos, depresiones y un gran sentimiento de culpabilidad (...) pero sabía que el arte le ayudaba a sobrevivir"39. De ahí su mítica frase: "l'art est une garantie de santé mentale" ("el arte es garantía de salud mental") ${ }^{40}$, que Delfín utilizó como eslogan para uno de los vestidos prêt-à-porter de la colección Intimidad $^{41}$.

\footnotetext{
34 Espacios de vida: las políticas del arte povera (hoja de sala). Museo Nacional Centro de Arte Reina Sofía, Madrid s.f., p. 1.

35 AT, Michelangelo Pistoletto. <http://www.madrenapoli.it/collezione/michelangelo-pistoletto/> (05.02.2018)

36 Otoño/invierno 2011.

37 PISTOLETTO, M. Venere degli stracci, 1967 (mármol y textiles 212x340x110 cm. Collezione Peppino Di Bennardo, Napoli. Conservado en MADRE · Museo d'Arte Contemporanea Donnaregina, Napoli).

38 DELFín, D. Referencias. Todo lo que me toca en la vida se acaba desvelando en mi trabajo [Curso Magistral Ideas y Emociones], Universidad Internacional Menéndez Pelayo, Santander (03.07.2013).

39 QUIROSA GARCÍA, V. "Y la nave va: plástica contemporánea en los límites de lo establecido" en Litoral. Revista de poesía, arte y pensamiento núm. 263, Torremolinos (Málaga), 2017, p. 201.

40 LEMARQUIS, P. Portrait du cerveau en artiste, Odile Jacob, Paris 2012, p. 158.

41 Otoño/invierno 2008. Dicha prenda no se mostró en la pasarela, fue una adaptación de la colección exclusiva para tienda.
} 
En la citada colección no faltaron las referencias a la artista francesa. De hecho, abrió el desfile con un modelo ataviado con una sudadera, pantalones, guantes y capucha, realizados con retales cosidos de manera desigual, como hiciera Bourgeois, dando vida así a las conocidas esculturas de la autora. La fabricación de este tipo de obras textiles también sirvió de inspiración a Pedro Almodóvar, amigo de Delfín, en su película La piel que habito ${ }^{42}$. En ella Elena Anaya, en el papel de Vera, rasga las pocas telas que Robert Ledgard, interpretado por Antonio Banderas, pone a su disposición y fabrica las esculturas a la manera de Louise Bourgeois. La unión entre David y Pedro va más allá de las influencias, ya que Delfín fue el encargado de vestir a los azafatos ${ }^{43}$ de Los amantes pasajeros ${ }^{44}$.

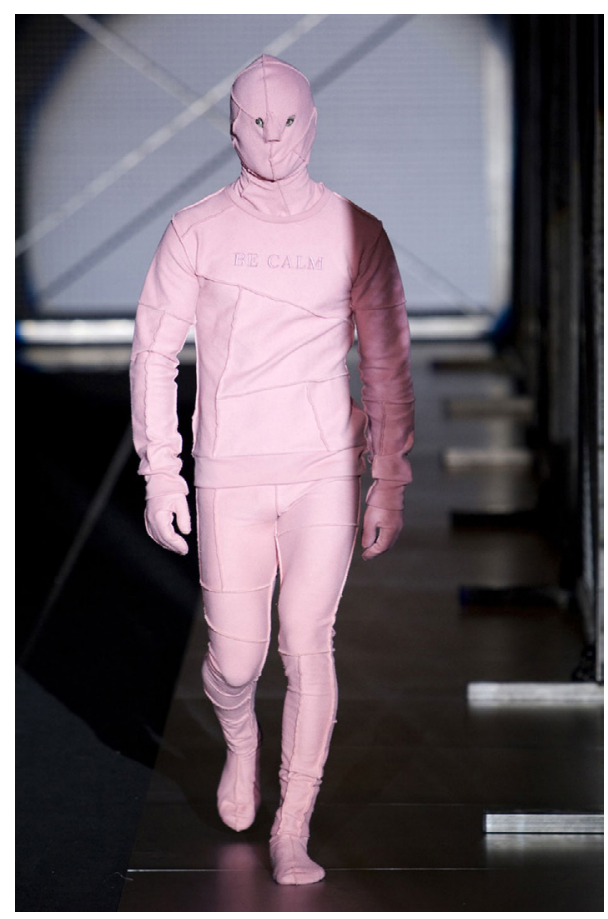

Fig. 5. Intimidad, otoño/invierno 2008.

\subsection{Le Corbusier}

En el curso magistral "Ideas y Emociones" que David capitaneó en 2013 dejó entrever su interés en dedicarse única y exclusivamente al diseño, explicando que la labor de aquellos directores artísticos, trabajadores de firmas internacionales que sólo crean, en su caso parecía ser una utopía ${ }^{45}$. La gestión de su empresa robaba

\footnotetext{
42 EI Deseo P.C. 2011.

43 AMARO MARTOS, I. "La Fábrica Almodóvar: vestuario al servicio del cine” en Actas III Congreso Internacional Historia, Arte y Literatura en el cine en español y el portugués. CIHALCEP2015, Universidad de Salamanca, Salamanca 2015, tomo II, p. 77.

44 El Deseo S.A. 2013.

45 DELFín, D. El negocio de la moda [Curso Magistral Ideas y Emociones], Universidad Internacional Menéndez Pelayo, Santander (05.07.2013).
} 
gran parte de su tiempo, y el arte ocupaba pequeñas pinceladas de su jornada. La situación de crisis afectaba a la producción y limitaba los resultados, sobre todo si hablamos de materias primas. Tan crítico contexto implicaba la disminución de los gastos. Este entorno precario fue el germen de la colección Katharsis ${ }^{46}$. La explosión de color que en ella se vivió no fue, sino, un derroche de creatividad en épocas económicas bajas, hasta el punto de llegar a replantearse hacer una colección con las muestras de tejidos que los proveedores llevaban a su taller.

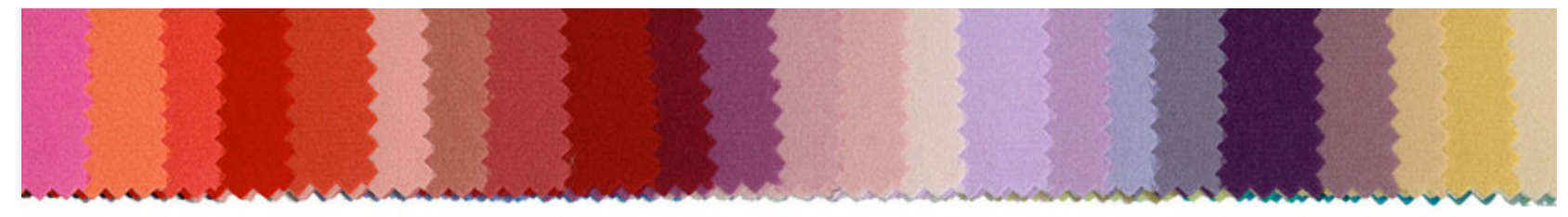

\section{KATHARSIS}

SPRING SUMMER 2012

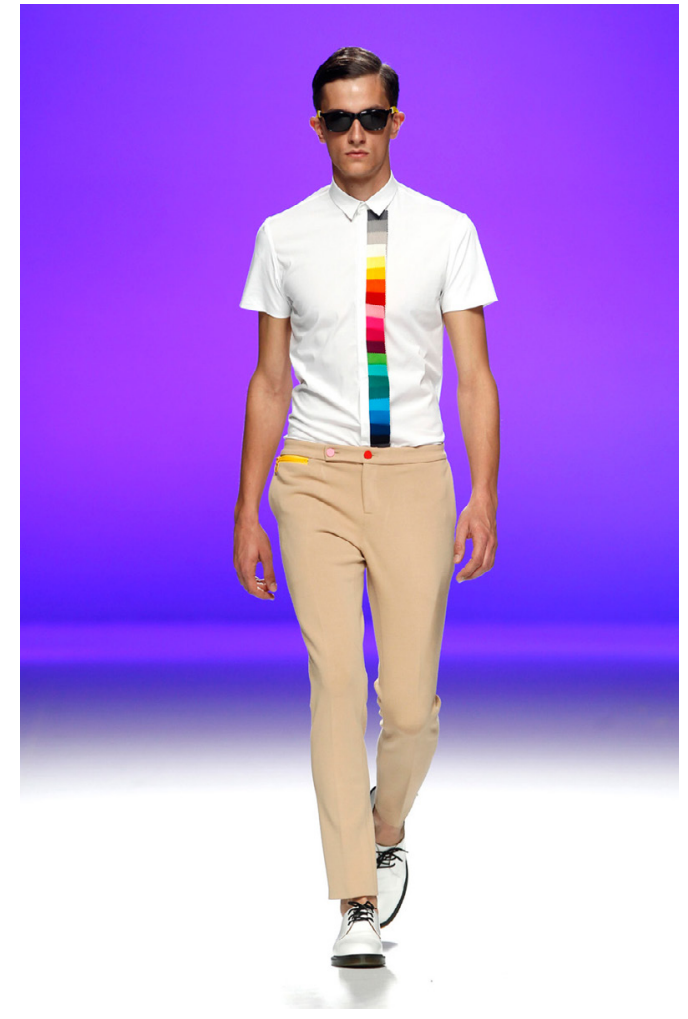

Fig. 6 y 7. Katharsis, primavera/verano 2012.

El resultado se dejó ver en camisas con degradaciones de color realizadas a base de pequeños retales, que también ocupaban faldas enteras, bordes de bolsos, etc. Ese mismo juego de muestras ocupó camisetas, 
vestidos y ropa de cama, añadiendo el nombre de cada color a modo de pantone de Le Corbusier. Mientras que el arquitecto suizo-francés denominaba los colores en función del efecto que éstos producían en la arquitectura ${ }^{47}$, el diseñador malagueño colocó nombres originales y propios a cada uno de los tonos de esta gama, adjuntado al lado de cada uno de estos recuadros la denominación con su reconocidísima caligrafía ${ }^{48}$.

Las obras arquitectónicas de Le Corbusier influenciaron también los proyectos de interiorismo de David Delfín. Lo podemos comprobar en las habitaciones que diseñó para el hotel Finca de los Arandinos, en Entrena (La Rioja). Se trata de una decoración de colores fríos y líneas rectas, dejando protagonismo al hormigón, como hiciera el arquitecto. El diseñador añade un mobiliario vintage de los años 50 y 60 , que aporta una imagen más acogedora del espacio, adaptando sus ideales estéticos a la funcionalidad para la que fueron pensadas estas habitaciones ${ }^{49}$.

\subsection{Santiago Ydáñez}

Del 8 de julio al 15 de septiembre de 2016 pudimos ver la exposición "Blank Canvas/arte-moda" en el Centro Cultural Baños Árabes, ubicado en el palacio de Villadompardo de Jaén. En ella se expuso un cuadro gigante de Santiago Ydáñez y, junto a él, una imagen de una de las camisas de David Delfín de su colección Inferno ${ }^{50}$, que supone el culmen de la trilogía conformada junto a No one ${ }^{51}$ y El tiempo de los monstruos ${ }^{52}$. El desfile, teñido de negro en la mayor parte de los looks, significó el paso del luto al alivio, produciéndose una reducción de la oscuridad hasta alcanzar el blanco más puro. El "no color" fue el fondo elegido para disponer las imágenes del artista giennense.

Ydáñez no crea historias, sino sensaciones que envuelven al espectador, a través de pinceladas rápidas e impulsivas, cargadas de energía, fuerza y expresividad ${ }^{53}$. Su obra iconográfica extrema está centrada en los rostros embarbados con espuma de afeitar, mostrando forzadas actitudes de ambigua representación y significado abierto ${ }^{54}$ Precisamente fueron estas imágenes las elegidas por David para las camisas de Inferno. "Una de las características que distinguen a Ydáñez con sus rostros es su fuente de inspiración, ya que la mayoría están basados en su propia cara maquillada" 55 .

\footnotetext{
47 Le Corbusier. Claviers de Couleurs, IGP, s.c. s.f.

48 DELFÍN, D. Desplazamientos [Curso Magistral Ideas y Emociones], Universidad Internacional Menéndez Pelayo, Santander (03.07.2013).

49 Un recorrido por la obra de DAVID DELFÍN, 2017 <https://www.fincadelosarandinos.com/recorrido-la-obra-david-delfin/> (08.02.2018)

50 Otoño/invierno 2015.

51 Otoño/invierno 2014.

52 Primavera/verano 2015

53 El CAC de Málaga presenta "El corazón manda" de Santiago Ydáñez. 23 de junio al 15 de octubre de 2017 (nota de prensa). Centro de Arte Contemporáneo de Málaga, Málaga 2017, pp. 1 y 2.

54 PALOMO, B. "Del Banco de Granada a Sandunga" en Laboratorio de arte, núm. 16, p. 353.

55 SÁNCHEZ, D. [Diario Jaén, 5 de octubre de 2010]. Cit. en: ALMANSA MORENO, J. M./MARTÍN ROBLES, J. M. 50 años de artes plásticas en Jaén. Creación, medios y espacios (1960-2010). Instituto de Estudios Giennenses. Colección Investigación, Jaén 2016, p. 612.
} 
Ciertamente el influjo de este artista y su presencia en el desfile fue más que reseñable. "Santiago Ydáñez nos sitúa por la iconografía de lo artísticamente incorrecto, por aquellos territorios donde la trasgresión adquiere cartas de naturaleza, donde la pintura se vale de una serie de excesos para desarrollar una expresionista realidad con el cuerpo humano posicionando sus más provocadoras actitudes" 56 . Algo que conjuga perfectamente con Delfín, y más en esta colección. Los tonos grisáceos que conforman estos autorretratos, de exagerada expresividad, conectan con el espectador y transmiten infinidad de emociones ${ }^{57}$. A su vez, juegan con la paleta empleada por David motivado por las obras de Ydáñez, hasta el punto de abrir el desfile con un modelo con máscara negra, extraído de una de las obras del giennense ${ }^{58}$.
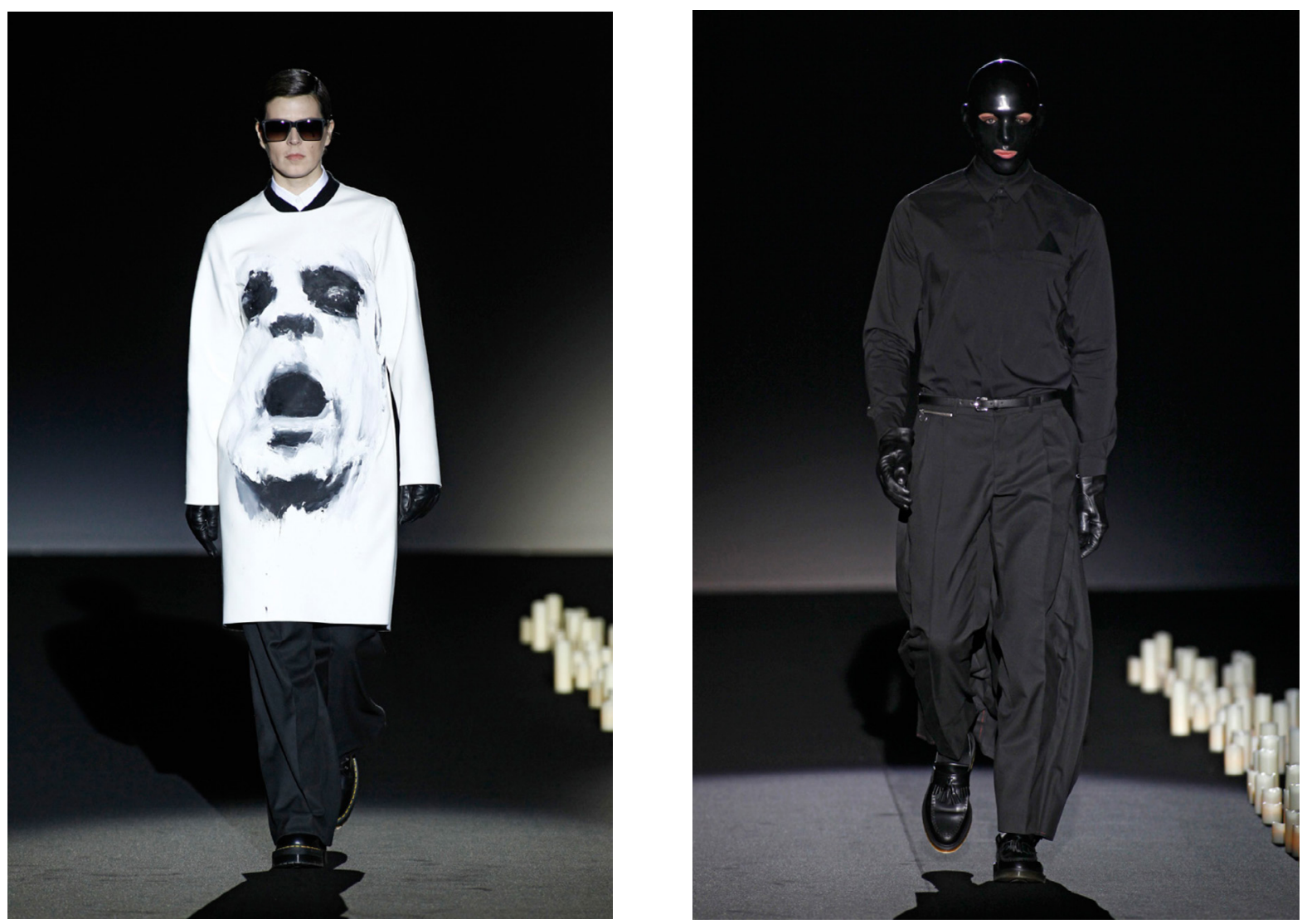

Fig. 8 y 9. Inferno, otoño/invierno 2015

56 PALOMO, B. "Del Banco de Granada a Sandunga" en Laboratorio de arte, n 16, p. 353.

57 ALMANSA MORENO, J. M./MARTÍN ROBLES, J. M. 50 años de artes plásticas en Jaén. Creación, medios y espacios (1960-2010). Instituto de Estudios Giennenses. Colección Investigación, Jaén 2016, p. 611.

58 YDÁÑEZ, S. Sin título, 2011 (acrílico sobre lino 75x75 cm), <http://santiagoydanez.com/works/2011.html?lang=en> (08.02.2018) 


\section{Conclusiones}

Desde que la moda, como sucesión de tendencias efímeras y veloces, surgiese en el siglo XVIII, la sombra de la superficialidad ha nublado su desarrollo creativo. Este contexto perdura aún en el siglo XXI, a pesar de que la museografía crítica haya contribuido a ensalzar el carácter artístico del diseño de indumentaria. En este contexto arcaico, donde triunfa la falta de contraste informativo, los medios de comunicación vilipendiaron el debut de David Delfín sobre las pasarelas. Con perspectiva ahora podemos señalar que incluso la prensa especializada atacó Cour des Miracles sin ni siquiera investigar e intentar comprender el bagaje históricoartístico que había tras la colección.

Conforme fueron pasando las temporadas, los periodistas fueron comprendiendo que David Delfín no era un diseñador como los demás. Su trabajo no podía ser descrito como si de un entretenimiento cultural se tratase. De hecho, en los últimos años se limitaron a describir la legión de fans que lo acompañaban en sus desfiles, obviando la profundidad de sus propuestas. Quizás porque para entender el trabajo del malagueño no bastaba con estar al pie de la noticia, sino que hacía falta ir más allá, informándose de sus ideas y sus emociones.

A veces ni siquiera bastaba con entrevistar al diseñador, ni con conocer el eje vertebrador de su discurso, había que indagar en sus referentes artísticos. Más que un trabajo de periodismo, se trataba de una crítica de arte. Porque David Delfín no fue un diseñador de moda al uso, fue un artista, del Renacimiento, de los que trabajan todas las artes y desplegaban imaginación en cada uno de los ámbitos del diseño. O de un "genio", ese artista multidisciplinar que en el siglo XIX se caracterizó por la incomprensión, el trabajo febril y la búsqueda o creación de un nuevo lenguaje.

Para conocer al genio y comprender su legado, desde el punto de vista estético y conceptual, era necesario ahondar en las producciones de otros artistas, por la fuerte aportación que éstos ejercieron en su desarrollo creativo. Así, hemos visto como Joseph Beuys, René Magritte, Buñuel, Michelangelo Pistoletto, Louise Bourgeois, Le Corbusier y Santiago Ydáñez han contribuido a las colecciones de Delfín. Sobra decir que han faltado muchos otros que también hicieron mella en su obra, ya sea por gusto o de forma efectiva, como Divine, John Waters, Marisol, Lola Flores o Alaska. Sean artistas "de museo", pertenecientes a la cultura popular, o directamente considerados trash, lo que está claro es que la obra de David es rica en influencias, difícilmente entendida sin el conocimiento previo de la trayectoria de estos creadores.

Si bien es cierto que las emociones fueron vitales en su discurso artístico, motivadoras de la mayor parte de sus colecciones y aportaciones a tantos otros ámbitos del diseño, en esta ocasión hemos preferido comenzar estudiando las puntuales y complejas aportaciones que otros artistas y estilos, o corrientes artísticas, tomaron parte en su devenir. Para la compresión de la base emotiva de David Delfín convendría plantear una nueva investigación, ahondando en la concepción psicoanalítica que caracterizó a Delfín. Para ello, habría que partir de la dificultad que supone estudiar, desde el ámbito científico, detalles tan personales y, en ocasiones, subjetivos como es la biografía de un artista. 